\title{
Population Attitudes and the Spread of Political Violence in Sub-Saharan Africa ${ }^{1}$
}

\author{
ANDREW M. Linke \\ Institute of Behavioral Science, University of Colorado Boulder \\ Sebastian Schutte \\ Zukunftskolleg and Department of Politics and Management, University of Konstanz
}

AND

Halvard BuHaug

Peace Research Institute Oslo and

Norwegian University of Science and Technology

\begin{abstract}
One of the most powerful predictors of violent political conflict is proximate violence in space and time. This spatiotemporal pattern has been identified between countries as well as within them. What explains this clustering is less clear, and different studies point to dif ferent mechanisms. Focusing on sub Saharan African states, we exam ine whether population attitudes may contribute to the spread of political violence at subnational scales. In a quasi experimental research design using georeferenced survey data of 18,508 respondents for 162 administrative units across 16 countries, paired with precisely georefer enced conflict event data we find that popular acceptance of (the legitimacy of) the use of physical violence is positively associated with subsequent conflict events. Furthermore, the combined effect of nearby violence and approval of violence is stronger than either condition alone, implying a diffusion effect. While we find some evidence that conflict events affect later public opinion, our final models control for violence that occurred before the survey data were gathered. The fact that we include such violence in our analysis suggests that the reported results cannot be dismissed as merely reflecting a reverse causal rela tionship.
\end{abstract}

What social conditions facilitate the spread of political violence? According to conflict studies scholarship, the catalysts may be economic, political, geographic or cultural, or any combination among these. Despite often relying on individual-level explanations for conflict patterns (explicitly or implicitly), political violence analyses often lack supporting empirical data representing

\footnotetext{
${ }^{1}$ We thank panel participants at the 2014 International Studies Association meeting in Toronto, ON for helpful suggestions about how to improve our work. We also thank the editors of this special issue and are grateful for helpful suggestions from Kristian Skrede Gledtisch, Nils Petter Gleditsch, Ragnhild Nordås, Siri Camilla Aas Rustad, Andreas Forø Tollefsen, Jonas Nordkvelle, and Anja Shortland. Earlier versions of this material were presented at the 2013 Association of American Geographers Annual Convention and seminars at the Peace Research Institute Oslo and Uppsala University. Finally, we thank our reviewers for offering us helpful constructive criticisms.
} 
individual views and beliefs. Where individuals are viewed as important actors in conceptual models of violence, their role is often presented in game theoretical terms, rational choice models, or is inferred from aggregate data.

Individuals are certainly represented in the framework that most conflict researchers use, but comprehensive and cross-national disaggregated survey data are not often used to measure actual attitudes of populations. One body of conflict research that relies heavily on the analysis of local population attitudes (sometimes using surveys) is the study of violent insurgency and rebel group support. From within that collection of work, we draw upon the argument that violence is most easily carried out by militants when they have at least some sympathy from the members of a local community. Beyond merely establishing an empirical link between attitudes and conflict in African states, we examine how collective opinion in an area may explain the diffusion of low-level conflict into that area. While many diffusion studies assume a uniform risk for the spread of conflict from one area into another, we identify the profiles of areas that are most likely to be affected.

Non-civil war political violence encompasses all varieties of potentially deadly conflict related to presidential or local elections, territorial disputes, cross-border pastoralist raiding activity, and other physical violence such as assassinations. In Africa, during recent decades, low-level political violence has increased relative to formal civil war (Straus 2012), and such countries as Côte d'Ivoire, Kenya, Zimbabwe, and Nigeria have experienced it in abundance throughout recent years. In this article, we hypothesize that the observed rate of conflict in a given area will be linked to past levels of support for the use of violence in that same area. In this sense, public opinion shapes the baseline conflict risk-whereas exogenous events (such as a controversial election result or an economic shock) may act as triggers - and explains the timing of the violence outbreak. As an extension of this logic, we also propose that the attitudes in a region may contribute to the expansion of ongoing conflict into that area, to the extent that local residents support the practices of those who commit violence.

To test our general expectations, we use Round Three (2008) of the Afrobarometer survey data (described in detail below), paired with fine-resolution conflict event data from the Armed Conflict Location and Event Dataset (ACLED). ${ }^{2}$ The Afrobarometer data are particularly useful for this purpose, because the survey asks specifically whether individual respondents approve of using political violence "in support of a just cause" (Afrobarometer 2008:23). We propose that attitudes influence conflict contagion, while we fully realize that preceding violence could also impact opinions (see also Linke and O'Loughlin this issue). Illustrating such an effect below (though it disappears after controlling for unobserved country-level influences), we control for prior conflict levels in all of our models.

In subsequent sections, we briefly review some literature on contemporary conflict diffusion and introduce our contribution to this collection of work. We present three specific propositions about the geographic diffusion of conflict. The survey, violence, and population data that we use are outlined in detail in the empirical data section. We then explain the quasi-experimental method that we use, followed by documentation and discussion of the analysis results and some robustness tests. The article ends with a reflection on future avenues for the practicable extension of this work.

${ }^{2} \mathrm{We}$ incorporate another conflict dataset in the appendix and find general agreement for the significance of the main result. 
The Spatial Clustering of Conflict

No social phenomenon takes place in a geographic vacuum. Earlier research has documented that political violence clusters at global and interstate scales. There are multiple explanations for why conflict spills over geographic boundaries. At the international scale, shared borders provide the opportunity for violence between neighboring states (Siverson and Starr 1990; O'Loughlin and Anselin 1991), often as a result of territorial disputes (Reed and Chiba 2010; Gibler and Braithwaite 2013). Conflict may cluster as a result of underlying factors such as regime type (Gleditsch and Ward 2000; Danneman and Ritter 2013; Maves and Braithwaite 2013) or poverty (Murdoch and Sandler 2004; Buhaug and Gleditsch 2008), ethnic group distributions that cross political boundaries (Gleditsch 2007; Forsberg 2008; Cederman et al. 2013), or the movement of militants across porous borders (Prunier 2009; Salehyan 2009; Braithwaite 2010) .

Subnational diffusion and clustering of violence also occur due to a number of different factors. Political violence (in the context of insurgency) often clusters in episodes of conflict along roads, due to their strategic and logistical importance (Zhukov 2012). Schutte and Weidmann (2011) suggest that violence exhibits varying types of spatial diffusion- "relocation" and "escalation"-dependent upon the type of war in question (regular or irregular). In their modeling of the escalation of all forms of war, the original location that was the source of conflict remains violent during irregular war instead of transitioning to peace; a transition to peace is more likely to take place with frontline (regular) warfare. In his study of electoral violence in India, Wilkinson (2004) argues that conflict clusters in electoral constituencies according to the degree of political party competition experienced. O'Loughlin and Witmer (2012), in a study of Russia's North Caucasus, suggest that patterns of conflict diffusion are driven by an ideological shift from ethno-nationalism to Islamism among insurgents. Similarly related to the operational influences of ideology, Toft and Zhukov (2012) suggest that insurgent activity spreads more quickly to new locations under a counterinsurgent policy of "punishment" (offensive action) than through other strategies. Additional examples of subnational research have shown that conflict diffusion models help us to understand ethnic conflict (Weidmann and Ward 2010) and insurgency in Iraq (Braithwaite and Johnson 2012; Linke, Witmer, and O'Loughlin 2012).

These studies are all closely related to our work, because they concern structural, ideological, and institutional explanations for space-time dependencies among conflict events. Our contribution is to address the question of how population sentiments and political opinions also play a role, empirically measured in georeferenced surveys. Many conflict diffusion studies use the language of epidemiology (for example, Zhukov 2012) and infection (for example, Braithwaite 2010). Our argument is that a local population's views about the use of physical violence may allow conflict to "infect" a new "host" area. This is a bottom-up view of the role that individuals play in conflict, rather than a top-down model based only on logistical (for example, military) considerations. Importantly, we also focus on political violence below the conventional thresholds for civil war and study forms of low-level conflict that are increasingly common in many African societies.

\section{Propositions: The Conflict Diffusion Model}

Many of the explanations for conflict clustering that we considered above are intuitive - and tell part of an important story about conflict processes. Nevertheless, our work contributes to the conflict studies literature in addressing a major 
theoretical question about the role of populations living in areas experiencing political instability. We strive to test an individual-level mechanism of how conflict may spread among locations. As have others in the field of conflict diffusion research (Checkel 2013), we use Gerring's causal mechanism definition, outlined as "the pathway or process by which an effect is produced or a purpose is accomplished" (Gerring 2007:178). In fitting with the tenets of human geography scholarship (for example, Agnew 1987), causal mechanisms are specific to social contexts. For example, a causal pathway is decidedly "relational," according to some scholars (Falleti and Lynch 2009). The fact that explanatory mechanisms can be context dependent falls in line with the highly localized data and analysis that we employ below. As we have indicated, the logic for this basic concept can be found in studies of insurgency and rebellion (Kalyvas 2006; Kalyvas and Kocher 2007; Lyall and Wilson 2009; Condra et al. 2010; Lyall 2010; Kocher, Pepinsky, and Kalyvas 2011; Zhukov 2013). The theoretical argument in this body of research states that population attitudes and beliefs define the possibility of violence taking place, because a local population either protects or betrays those individuals who are willing to commit violence. Usually, the question for these scholars is whether collateral damage committed by either side of an armed campaign will sway the collective opinion in an area-so that either the incumbent/ occupying force or insurgents/militants have a strategic advantage over their opponent. The strategic advantage materializes in the decision that individuals or groups make to turn in, or alternatively support, the efforts of conflict actors.

We argue, however, that individual-level attitudes complement this strategic logic. One could assume that the presence of violent beliefs in an area represents a necessary condition for violence; there must be a contingent willing to commit violent acts. But, the diffusion aspect of our analysis makes the story more complicated. While a co-conspirator (co-ethnic, or otherwise ideologically aligned) who approves of using violence makes an attacker's job easier in location A, the absence of a conflict-approving colleague does not perfectly prohibit an individual from nearby location B from committing an attack in location A. This would suggest that violence approval in an area has an effect on the probability of violent clashes, without being a necessary condition in a deterministic sense. There are two important considerations (related to the approval of violence) being applied in this framework. The first regards the type of conflict we investigate and the second considers the reaction from a victim (or targeted) community/region, given an initial attack or impending threat of an attack. Consider that in one scenario, a group comes under attack and flees, resulting in a single violent event. In a different scenario, that group comes under attack and fights back, resulting in a continuation of serious violence. In the second scenario, the process driving severity and escalation of conflict can be observed and is related to the local population's decision to engage an opponent violently. In other words, the logic driving the location of an initial act of one-sided violence may not depend on the local population's beliefs as a necessary condition, but popular approval of violence can explain variation (especially severity and duration of events) in future cycles of violence along multiple causal pathways.

For example, facing an impending attack (such as violence nearby), the targeted/victim population may flee. As a result, the level of conflict subsequently taking place would be relatively low in comparison with a scenario in which a local population made a decision to fight (it has been shown that, often, peace follows an initial advance of combatants-because the population is either forced to flee, is subdued by violent means, or loses motivations to take either side in the conflict [Kalyvas 2006]). Furthermore, given notice of an impending attack, a person who disapproves of using violence (under any conditions) is apt to be more likely to report violence to authorities or powerful leaders; this reporting might stop the event from taking place. Perpetrators of violence are 
more likely to find a sympathetic environment for their activities in regions where violence is widely viewed as a legitimate means of political expression; they are more likely to find violent resistance to any advances or initial attacks; and they are less likely to be turned into authorities (which could lead to a peaceful outcome).

We make three specific propositions in this study. First, we expect that violence in a given area will be significantly related to conflict in nearby locations. We anticipate identifying this straightforward relationship based on the conflict studies literature concerning spillover effects and diffusion. Second, the level of violence in a given area will be a function of prior support for the use of violent politics among the population of that area. There are direct and indirect reasons that collective public opinion within a territory may explain conflict diffusion, as we have explained above. Directly, a person who openly approves of using violence may be seen as more likely to engage in violent acts than a person who does not; and a person who believes in the utility of violent actions may be more willing to violently respond to an initial attack. Indirectly, a person who approves of violence may be more likely to harbor someone from outside the community whose aim is to perpetrate violence (if their positions align). Third, the combined effect of high approval of violence and nearby previous violence will be stronger than the effect of nearby violence alone. This third proposition is the observational implication of an unobserved conflict diffusion mechanism based on the theoretical role of individuals. To date, no study has addressed this possible mechanism for conflict in a comprehensive spatial analysis framework for multiple African countries.

We identify two important alternative explanations for the rate of conflict in an area or the spread of conflict into the area and account for them in the following analysis. Many observers consider population size to be an important explanation for the spatial distribution and observed levels of violence. This may be due to a simple probabilistic relationship; the chances that a perpetrator of violence will be found in an area rise with the total number of people living there. Other explanations include an information-sharing phenomenon, where ideologies and knowledge (for example, about an attack) are disseminated more effectively in densely populated areas than in sparsely populated and remote regions (Shapiro and Weidmann 2011). Even in large marginalized or remote areas, the population-conflict link has been established (Raleigh and Hegre 2009; Theisen 2012; Tollefsen and Buhaug this issue).

In addition to population size, socioeconomic conditions in a subnational region may be linked with the level of conflict there (Buhaug et al. 2011). For example, low incomes and relative economic marginalization are a key component of the "opportunity cost" model of participating in violence and also consistent with the grievance explanation. When an individual's socioeconomic status is low, the incentive for engaging in conflict to supplement his/her income is high (Grossman 1991; Miguel, Satyanath, and Sergenti 2004). Regarding terrorist violence, scholars argue that the loyalties of local populations may be bought, which increases the chances that a militant will be able to carry out his or her agenda (Berman et al. 2011a). For example, Dube and Vargas (2013) show that when international commodity prices for a key agricultural good (coffee) fall, rural Colombian populations supplement their incomes by siding with Revolutionary Armed Forces of Columbia (FARC) militants. Berman, Shapiro, and Felter $(2011 \mathrm{~b})$, on the other hand, find little evidence for the argument that low incomes foster terroristic (insurgent) violence in Afghanistan and Iraq (also Blair et al. 2013 for Pakistan). In sub-Saharan African conflicts, the relationship between violence and subnational income levels may also exist. It is known, for example, that politicians often hire militants to intimidate electoral opponents. In the case of Kenya's 2007 and 2008 election-related violence, for instance, a 
prevailing "pattern" of the conflict was that "politicians and business people planned and enlisted criminal gangs to execute violence" (Kanyinga 2009:340). In the analysis reported below, we control for the possibility that these relationships exist in order to isolate the effect of a population attitude-diffusion mechanism.

\section{Empirical Data and Methods}

Despite the richness of the Afrobarometer survey data, it has rarely been used within the dedicated spatial framework that we have adopted. Commonly, the only geographic component of survey analyses are country-level fixed effects (or clustered errors at some spatial scale), and these are included in models to "control away" unexplained influences upon a given response (for example, Hutchison and Johnson 2011). Examples of surveys being used in a geographic framework exist, but the resulting analysis is usually confined to a single region/country. ${ }^{3}$ One example of a cross-national Geographic Information System (GIS) survey used in conflict research is provided by $\emptyset_{\text {stby, Nordas, }}$ and Rød (2009), but their analysis is designed to capture a socioeconomic surrogate from the surveys, to use in models of intrastate conflict onset as the outcome.

In order to test our stated propositions, we rely on the Afrobarometer Round Three survey data (2008). The survey covers 16 countries on the African continent. Question 51 of the Afrobarometer survey asks, "Which of the following statements is closest to your view? Choose statement A or statement B. A: The use of violence is never justified in [respondent's country of residence] politics. B: In this country, it is sometimes necessary to use violence in support of a just cause" (Afrobarometer 2008:23). Possible responses to the question are "agree very strongly with A," "agree with A," "agree with B," "agree very strongly with B," "agree with neither," and "don't know." We drop "don't know" responses from the following analysis. We code as approval of violence either agreeing or strongly agreeing with statement B. The final indicator that we use is whether or not the percentage of violence approval is above the average across units. ${ }^{4}$ Survey data for the key attitude measure is mapped in Figure 1 Panel A. Descriptive statistics for the survey responses are presented in Table 1 below. We georeference these survey data to administrative units so that they can be joined with other social, economic, and political data. ${ }^{5}$ To merge surveys with violent events data with temporal and spatial data, we record for each administrative unit the start and end dates of survey enumeration in each country. ${ }^{6}$

For every administrative unit in each country (for example, district), we calculate the proportion of residents who approve of using violence. We reduce the

\footnotetext{
For example, Bakke, O'Loughlin, and Ward (2009), Deluca and Verpoorten (2012), Blair et al. (2013), and Linke (2013), pair georeferenced violent events data to surveys in Russia's North Caucasus, Uganda, Pakistan, and Kenya, respectively.

${ }^{4}$ In the appendix to this paper, we test the effects of using a country-specific administrative unit level of support for violence (whether the proportion supporting violence for a given unit is greater than the country average instead of the continent-wide average). We find general agreement for the new key indicator (positive effect, significant), but the effect is weaker.

${ }^{5}$ We use GADM V 1.0 shapefiles projected originally in WGS 1984.

${ }^{6}$ Dates of enumeration are as follows: Benin, 2005.10.09 2005.10.28; Botswana, 2005.04.22 2005.05.10; Ghana, 2005.03.10 2005.03.21; Kenva, 2005.09.06 2005.09.28; Lesotho, 2005.07.06 2005.08.17; Malawi, 2005.06.16 2005.07.04; Mali, 2005.06.20 2005.07.07; Mozambique, 2005.06.13 2005.06.26; Namibia, 2005.02.13 2005.03.07; Nigeria, 2005.08.28 2005.12.31; Senegal, 2005.09.26 2005.10.08; South Africa, 2005.02.06 2005.02.28; Tanzania, 2005.07.21 2005.08.13; Uganda, 2005.04.12 2005.05.04; Zambia, 2005.07.29 2005.08.16; Zimbabwe, 2005.10.09 2005.10.28.
} 

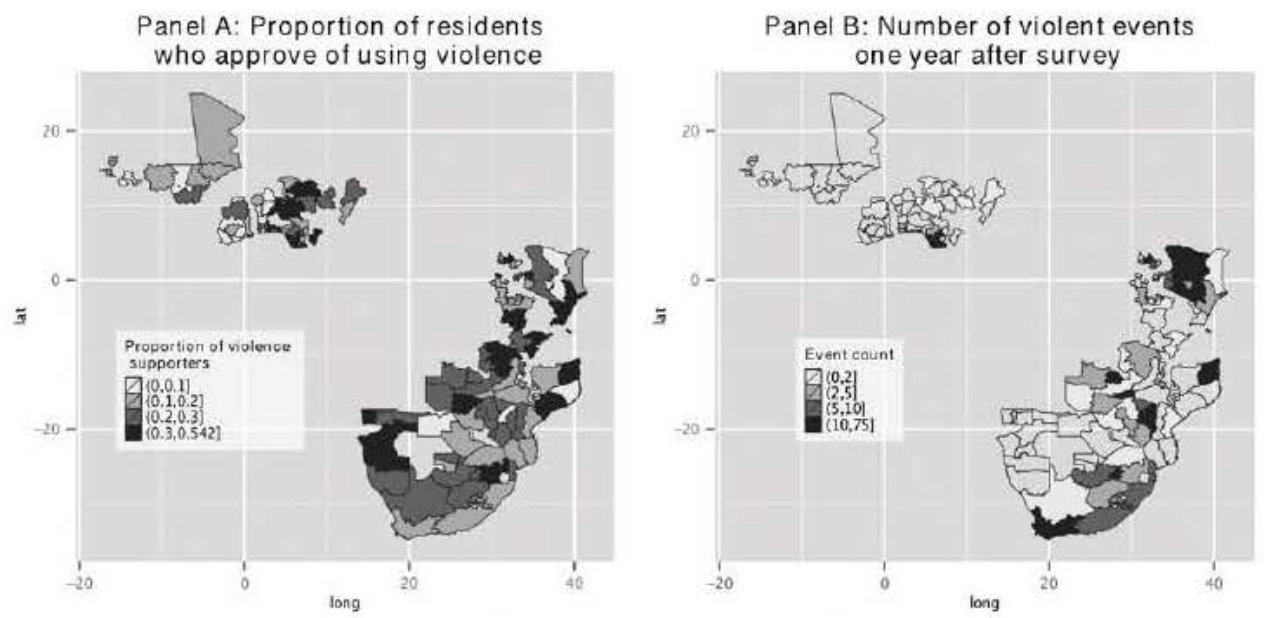

Fig. 1. The Spatial Distribution of Population Attitudes (Panel A, Left) and Observed Violence (Panel B, Right) for Subnational Administrative Units

(Note. We use all countries where the survey data exist and do not select only cases/countries where violence has taken place).

TABle 1. Descriptive Statistics for All Survey, Population, and Conflict Data after Dropping Adminis trative Units with Fewer than 50 Respondents $\left(\begin{array}{ll}N & 162\end{array}\right)$

\begin{tabular}{lccccl}
\hline & Sum & Mean & SD & Max & Min \\
\hline Population (log) & 2228.58 & 13.757 & 1.205 & 16.029 & 9.099 \\
Violence approval & 74 & 0.457 & 0.5 & 1 & 0 \\
Low SES & 53 & 0.327 & 0.471 & 1 & 0 \\
Presurvey event count & 950 & 5.864 & 17.558 & 166 & 0 \\
Post survey event count & 598 & 3.691 & 9.288 & 75 & 0 \\
Neighboring violence & 112 & 0.691 & 0.463 & 1 & 0 \\
\hline
\end{tabular}

risk of sampling bias by dropping administrative units from the final analysis data whenever information on representativeness is unclear (fewer than 50 respondents). We drop units of analysis after creating the spatial metric of nearby violence. Our concern for the number of survey respondents in an area is related to the representativeness of the sample in a "receiving" area, or the location that the violence is spreading into, and is not related to the "sending" area. In other words, it is important to know if violence is taking place nearby, whether or not we believe that the survey sample population in that nearby area is representative of the neighboring administrative unit. For attitude and control data, we care about the representativeness of the survey data in the area the violence spreads into, but the neighboring violence data are external to the survey instrument.

Georeferenced data on political violence events are taken from ACLED (Raleigh et al. 2010). ${ }^{7}$ We define the range of dates for aggregating the conflict data using the thresholds that mark the beginning and end of survey enumeration in each country. The range is one year before and after the survey. The post-survey violent event count for observations is mapped in Figure 1 Panel B. The conflict measure is simply a count of the number of events that took place

\footnotetext{
${ }^{7}$ In the appendix, we compare the main model estimate to those derived using conflict data from UCDP GED. The basic conclusion holds although the effect of population attitudes is weaker.
} 
in the pre- and post-survey time periods. For the nearby violence variable, we generate a binary indicator of whether or not conflict took place within any of the neighboring administrative units. We include events of relatively low severity, including rioting. In controlling for the prior level of violence, we use the number of events that took place in a given area. We control for prior levels of violence because they are a strong indicator of subsequent conflict. We test our propositions using spatial weights matrices for the three nearest neighboring areas.

We include the number of people living in an administrative unit (logged) as a control. Population data are derived from the raster-based Gridded Population of the World (GPW) v3 (CIESIN 2013) for the year 2000 (before the earliest period of survey enumeration). Overlaying administrative unit polygons above the GPW population data, we measure total population using a zonal statistic.

Because of the role that poverty may play in explaining conflict (Buhaug et al. 2011), we control for the socioeconomic status (SES) of a region. Subnational geographic income data for African states are notoriously lacking and as a result we again rely on survey data. For each of the subnational administrative units, we pool the number of respondents who reported (Q8A in the survey) that they had gone "often" or "always" "without enough food to eat" (Afrobarometer 2008:7). We code as one those administrative territories where the number of low-income respondents is higher than the average for all regions.

In addition to the control variable data described above, we test the effect of including country-level fixed effects in the treatment effect estimate (after matching observations). Doing this eliminates the potentially confounding unobserved processes that may influence conflict itself, the diffusion of conflict, and the attitude-diffusion mechanism that we have proposed. A number of country scale factors, such as political institutions, media reporting of violence, infrastructure, and terrain, may allow for conflict to spread in a manner that is variable from one setting to another. In poorly governed states without the institutional capacity to police populations, for instance, we might observe a stronger and more powerful transmission of conflict through population attitudes than in a setting of representative and well-governed regimes.

\section{Methods: Empirical Analysis of the Propositions}

A straightforward preliminary analysis indicates tentative support for all three proposed relationships (see Table 2). After the survey, the average number of conflict events in a district is higher (by 4.52 events) where the number of people who approve of violence is above average. Similarly, where there has been previous violence in nearby administrative units, the number of violent events is higher (4.29) than in territories that are not near to other prior conflict. In support of our third proposition, the average number of events is highest where approval of violence is above average and nearby violence has taken place

TABle 2. Differences in Violent Event Count Means Between Affected and Nonaffected (Treatment and Control) Observations of Conflict Events for the 1 Year Period Following Afrobarometer (2008) Survey Date

\begin{tabular}{lc}
\hline Proposition Indicator & $\begin{array}{c}\text { Mean Event Count } \\
\text { (Treat Control) }\end{array}$ \\
\hline Violence approval & 4.524 \\
Neighboring violence & 4.298 \\
Violence approval and neighboring violence & 5.817 \\
\hline
\end{tabular}


(5.81). Simple differences in means calculations are informative, but they should be interpreted with caution, as they do not control for the alternative explanations of conflict that we have identified above, including prior levels of conflict. In that sense, the pattern reported in Table 2 might reflect a reverse causal relationship, whereby violence affects future population attitudes rather than the theorized opposite effect.

To more properly analyze whether survey opinions or neighboring violence predict subsequent violence, we rely on Coarsened Exact Matching (CEM) estimates of Sample Average Treatment effect on the Treated (SATT). Commonly used quantitative methods are sometimes inappropriate for observational data (rather than experimental, or otherwise sample-based data sets), and we have remedied this issue by following the quasi-experimental approach. For example, researchers often rely on regression coefficient standard errors for determining whether a given indicator influences the risk of conflict. Where conflict and socioeconomic data do not constitute a sample of a larger population, the logic of using standard errors - quantifying the influence of sampling variability-has biased previous conflict research (see Ward, Greenhill, and Bakke 2010). To avoid this problem, our analysis follows the recent turn toward analyzing natural experiments quantitatively (for example, Rosenbaum 1989).

The algorithm that we use to assign survey administrative-unit observations to treated and control groups is outlined in detail by Iacus, King, and Porro (2011). The goal is to identify treated observations (for example, above-average level of violence approval) that are as similar as possible to other observations that did not experience treatment. Strata are then created for a range of the values for each control variable (here, population size, prior level of conflict, and socioeconomic status) and observations that fall within the same strata are considered similar. As noted above, we also examine the effects of controlling for unobserved country-level influences (which may be political, economic, or otherwise). This matching procedure is run without regard to the outcome of interest (conflict). Based on matching, we compare treatment and control groups under otherwise most similar conditions with regard to subsequent levels of violence to establish the treatment effect. We report balance improvement statistics, but in our analysis balance always is optimized.

Compared to the matching algorithm described briefly above, the treatment effect estimate that we use is relatively straightforward. Outcome $Y_{i}=T_{i} Y_{i}(1)+\left(1-T_{i}\right) Y_{i}(0)$, where $Y_{i}(0)$ is the potential outcome for control observation $i, Y_{i}(1)$ is the potential outcome if that unit $(i)$ is treated, and $T_{i}$ is the binary treatment status. We cannot observe $Y_{i}(0)$ with treatment for $i$, and similarly, $Y_{i}(1)$ is not known if $i$ is not treated. Because it is impossible to know what the level of conflict in an area would be if it had not been near to other conflict events, for example, counterfactual simulations of the conditions that would produce those values are estimated in the matching procedure. The final estimate of $T E_{i}=Y_{i}(1)-Y_{i}(0)$, across observations, is $S A T T=\left(1 / n_{T}\right) \sum_{i \in\left\{T_{i}=1\right\}} T E_{i}$. We report $95 \%$ confidence intervals for the point estimate of each key proposition variable's influence on the level of conflict in an area.

In our results, we report two statistics that measure improvement in balance for the data after matching. The $L 1$ statistic is a summary multivariate distance metric of how closely the covariate values align between the treatment and the control group. We might want to know, for example, how similar the population size of observations in the treatment group is relative to the population size of observations in the control group. $L 1$ provides this in the form of an estimate of control value profiles for each group, ranging from 0 , where the distribution of values is exactly comparable, to 1 , where they are completely distinct. A lower $L 1$ value is desirable. We present these statistics because they will be of interest to researchers familiar with the matching design we employ. Local Common 
Support (LCS) is a similar measure based on similarity of covariate ranges between the control and treatment groups. For LCS, a higher percentage is preferable, indicating greater similarity for covariate values. Similar to the case of the L1 statistic, the LCS percentages would ideally be higher (toward 100\%). Finding such a match for observational data with a relatively small $N$ is, however, highly unlikely.

A technical concern for our matching analysis is the Stable Unit Treatment Value Assumption (SUTVA). There are two elements of the assumption. First, the treatment condition has the same effect on a unit regardless of how the unit came to be exposed (often interpreted as the treatment having a uniform effect across units). Second, the effect of the treatment condition for an observation unit is independent of the effect that the treatment condition has on other observation units. Stated generally, the second assumption means that units of observation are independent. Specifically, the treatment status (neighboring conflict) of any unit (administrative area) must not affect the potential outcomes (conflict) of the other units. This is the case because our methodological approach assumes that there is a single potential outcome for the treatment and, separately, control condition. Where there are overlapping treatment effects among observations, there is not a single potential outcome for a given unit.

By including covariates such as population size and poverty level, we hope to dampen any effects of violating the first SUTVA assumption. One might argue, for instance, that the treatment condition (neighboring conflict) is qualitatively different in an area with tens of thousands of people compared with an area that has one thousand. Similarly, someone might claim that the effect of nearby violence varies between poor and comparatively wealthy areas. We have also accounted for this possibility by controlling for the administrative unit's socioeconomic status. For our study, the more immediate concern is the second element of SUTVA, whereby an administrative unit could be influenced by the treatment condition of other units. To account for this problem, we match previous treatment assignment (for example, conflict) to the units (for a similar approach, see Schutte and Donnay 2014). We elaborate upon this in substantial detail in the Appendix.

In the following analysis, we estimate the influence of neighboring violence upon conflict (proposition one). Next, we measure the influence that local-level views about political violence have had upon subsequent violence (proposition two). Finally, we measure how combined above-average approval of violence and previous nearby violence affect levels of conflict (proposition three). As a corollary to these models, we finally estimate the effect of prior violence upon collective opinion about the use of violence. Because there is some evidence that violence may affect collective public opinion in each territory, we control for previous violence in every model below.

\section{Results}

Figure 2 presents the results of each basic model, and the results of each model after controlling for the other key indicator (that is, neighboring violence, after accounting for local attitudes and vice versa). All models include controls for prior conflict, population size, and socioeconomic status within each survey administrative unit. Supporting our first proposition, the presence of violence within a nearby territory strongly predicts conflict in an administrative unit, at 2.40 more conflict incidents $(+65.04 \%)$ on average than would be found in territories without neighboring conflict. This relationship holds even after accounting for the fact that local 

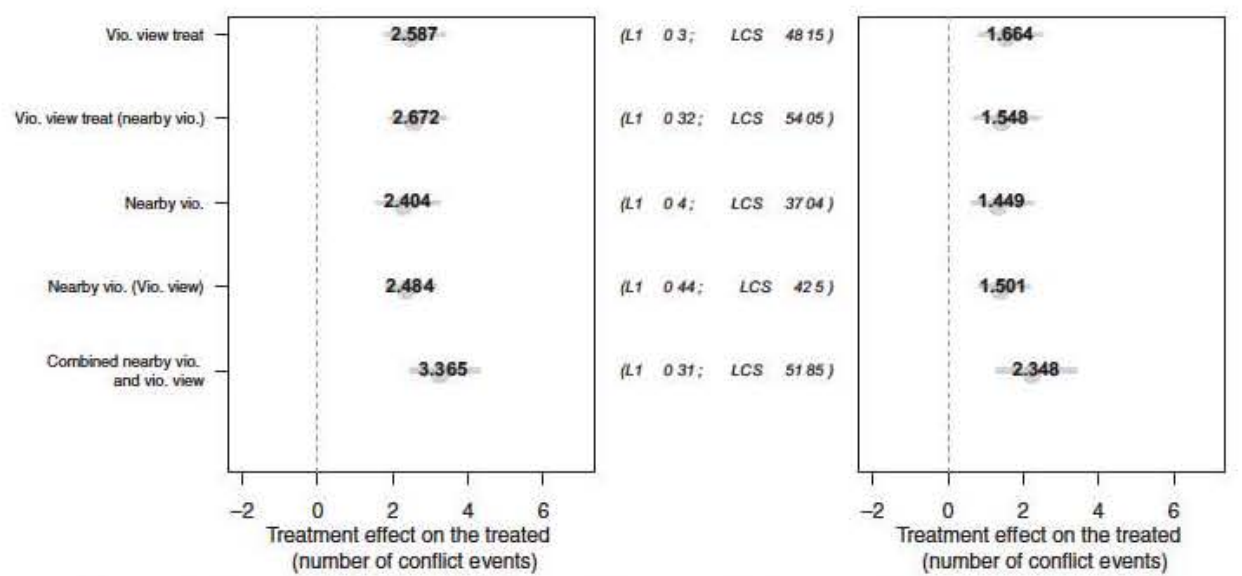

Fig. 2. Average Treatment Effects of Five Indicators Testing the Three Main Propositions

\begin{abstract}
(Notes. Balance improvement scores for the matched data used in each model are presented in the center ( $L 1$ and LCS). We present $95 \%$ confidence intervals. The right panel of the figure presents the treatment effect estimates after including country-level fixed effects. Matched data (and balance diagnostics) are the same for both because the fixed effects are used after the initial coarsened exact matching matching procedure. "Vio." means violence in the variable name).
\end{abstract}

attitudes (as illustrated below) also influence violence (+2.48 events, or $+67.20 \%)$. We interpret this finding as evidence of a geographic and temporal diffusion process taking place across African regions. To test the robustness of these findings, we include a country fixed-effects term in a second iteration of the models (Figure 2 Panel B), effectively controlling for any unobserved country-level influences upon conflict levels. The neighboring violence geographic diffusion indicator remains statistically and substantively significant. This suggests that, continentwide, the diffusion of violence among African subnational territories indeed is taking place, regardless of state-level characteristics.

Regarding proposition two, there is also evidence linking the approval of violence within administrative units and violence. As Figure 2 Panel A shows, there are a greater number of conflict events where violence is considered legitimate by an above-average number of survey respondents $(+2.58$ events, or $+70.09 \%)$. This result supports the claim that violence is at least in part contingent on regional-level beliefs about politics, and the effect remains statistically significant, although weaker, after controlling for country-specific characteristics. Because we have concluded that conflict diffusion is taking place (from proposition one), it is important to note that the effect of violence attitudes remains after controlling for neighboring violence.

As we have discussed above, the combined effect term (Figure 2 bottom, model five) is designed to understand how violence moved into an area. The central goal of this analysis is to test our third proposition, suggesting that one pathway between nearby conflict and later violence in a given area is pooled public opinion in that territory. We expect that the effect estimate for this combined term will be higher than the effect of either the attitudes or neighboring violence terms alone. We find that areas with above-average violence approval and nearby violence are at a much higher risk of conflict $(+3.36$ events, or 
$+91.3 \%$ ) than areas where peaceful views dominate and proximate violence has not taken place. Notably, this effect is maintained even after introducing country-level fixed effects (Panel B). Overall, the results suggest that collective political opinion within subnational regions of African states helps to explain the space-time diffusion of political violence. As we have argued in greater detail above, this relationship may emerge because people are willing to engage in violence individually, but also, indirectly, because they are willing to support or harbor the perpetrators of violence.

In the Appendix, we show that the basic statistically significant result for proposition three holds when a country-specific definition of our violence approval threshold is used (instead of comparing administrative units to the entire continent). However, an important caveat is that the influence of the combined term in this case is not greater than either estimate of nearby violence or attitudes about violence alone.

What explains the comparatively high levels of support for violence that are found in some administrative units and not others? If support for violence helps to explain later conflict (and we have found that it can), this would be important to understand. A host of different mechanisms explaining baseline support for violence is imaginable, ranging from traumatizing firsthand experiences of past violence to deeply held cultural beliefs about dispute settlements. However, the Afrobarometer surveys do not allow for definitive conclusions along these lines. We therefore focus our attention on exposure to previous violent events. As a corollary analysis to the work reported above, we now test whether violence within administrative units (prior to the date of survey enumeration) influences beliefs about the use of violence. Existing research has suggested that violence may harm social attitudes, as conflict experiences might be considered "radicalizing" events (O'Loughlin and ÓTuathail 2009). Specifically with regard to indicators of social trust, Levi and Stoker (2000) suggest that individuals' beliefs are at least partly a function of local social and political "contexts," and one important quality of a neighborhood context is existing/ongoing political violence. Hutchison and Johnson (2011) show that, across Africa, conflict in a country reduces trust in state institutions. Using experimental evidence in Nairobi, Becchetti, Conzo, and Romeo (2011) find that exposure to conflict has a harmful effect on trustworthiness. Also in Kenya, Dercon and Gutierrez-Romero (2012) show, using survey data, that exposure to the country's 2007-2008 post-election violence "increased support toward lawlessness." While important differences may remain between individual- and locality-level exposure to conflict, we investigate the generalized relationship here. Not all research, additionally, supports the link between exposure to violence and subsequent support for violence. Blair et al. (2013), for example, find that Pakistanis living in urban areas are less likely to support militants, because they are exposed at greater rates than nonurban respondents to the externalities of violent acts committed by extremists.

To test the impact of violence upon public opinion, we estimate the same quasi-experimental SATT models as above with prior conflict as the treatment indicator. The outcome variable is whether or not an administrative unit has an above-average percentage of violence supporters. Figure 3 presents the treatment effects for three models. The first controls for socioeconomic status and population size (as in all of the models above). Areas with previous violence are $62.22 \%$ $(+0.28 \mathrm{TE}$ share of mean 0.45$)$ more likely to have above-average levels of support for violence, controlling for other influential factors. This general finding disappears, however, when a control for neighboring violence is added to socioeconomic status and population, and also is not statistically significant when country fixed effects are incorporated into the SATT estimate after matching. Our attempt to understand the link between attitudes and violence comes full circle with the Figure 3 model of how conflict conditions collective public opin- 


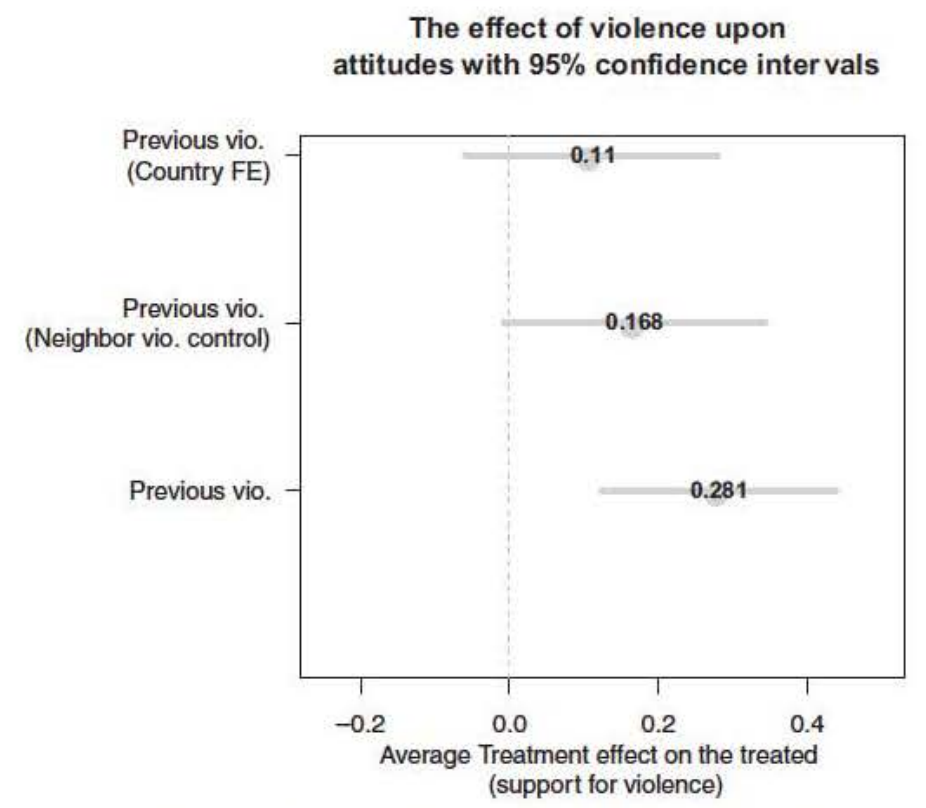

Fic. 3. Average Treatment Effects of Violence Preceding the Afrobarometer Round Three Survey Upon Level of Approval of Violence in Each Administrative Unit

(Notes. Treatment in this model is whether there was previous violence in an administrative area and the outcome is whether or not the territory has an above-average (continent-wide measure) level of support for violence. "Vio." and "Treat" mean violence and treatment in the variable names).

ion. There is some evidence-if somewhat inconsistent-that violence influences public opinion about using violence. Also, our result falls in line with existing research that finds a cyclical and interactive quality to instability in the developing world. Unobserved qualities of the countries included in this study also appear to affect the link between previous conflict and attitudes.

\section{Conclusion}

In this study, we have presented evidence that the level of political violence in a subnational African region is influenced by previous violence nearby. Support for our first proposition falls closely in line with existing conflict research that uses geographic diffusion and contagion models of violence. We also find that the rate of violence in an administrative area depends in part upon the attitudes of the population living there, controlling for prior conflict. Where a higher than average number of people approve of using violence to further a political agenda, the risk of conflict is substantially higher than it is in places where collective opinion is pacific. It is critically important that we have identified such an effect after controlling for previous violence. Finally, we find that political attitudes serve as a mechanism that explains how conflict spreads into subnational regions of a country. To round out our analysis of conflict diffusion, we also examined the link between conflict and popular opinion within administrative units. While attitudes play a role in conflict spreading, there is some evidence that conflict in turn plays a role in shaping attitudes.

This study represents an important contribution to the conflict studies literature, owing to several of its qualities. First, following recent work by conflict 
researchers, we use a fine-resolution analysis in contrast to a country-level approach. Second, we employ a uniquely georeferenced source of survey data to gauge the collective political opinion of subnational administrative units. To the best of our knowledge, this is the first application of such a spatial approach for multiple African countries. Third, we estimate a quasi-experimental model that is specifically designed to measure an explanatory mechanism; the identification of such mechanisms has been missing from many previous conflict diffusion analyses. Fourth, our article is guided by a theoretical research question that has received a great deal of attention in the conflict and political violence literatures. Specifically, we focus on how political attitudes in an area influence observed rates of conflict. In the manner that the literature suggests, we find that the spread of political violence depends in part upon the views and beliefs of the population living in an area. Finally, we examine how public opinion and political beliefs influence the diffusion of violence, without limiting our analysis to a single conflict-prone country. Because we include many relatively stable African countries, our findings may be generalized to a greater degree than the conclusions of some single-country studies.

There are several avenues for future research investigating the themes we have engaged. First, we have analyzed the interrelated character of political violence and population attitudes where survey data are available. Due to the availability of such data, our study is limited to less-severe (though still deadly) political violence. It is not possible for us to extend our conclusions to cases of large-scale civil war and utter state collapse; killing in Somalia, the Democratic Republic of Congo, and South Sudan is taking place under a different set of social realities than conflict in Kenya, Nigeria, or Uganda. Using creative research designs, it may be possible to evaluate our findings for independent surveys conducted in African war zones. ${ }^{8}$ Extending this analysis to other rounds of the Afrobarometer surveys is a possibility that would lend greater generalizability to the findings here (both over time and across the continent). Additionally, the survey data that we use are not experimental by design, which would ideally be the case. As we have mentioned previously, for example, we must rely on socioeconomic status controls measured simultaneously with the attitude data. A carefully planned long-term field experiment could remedy these issues and reveal substantial insights into the mechanism that we have proposed. Finally, although we would ideally have a time-series panel data set with each respondent revisited repeatedly over time, changes in individual beliefs are difficult to measure on a continental scale for thousands of respondents. Monitoring individuals over time, with follow-up surveys, would allow a more nuanced view of how their role in conflict cycles develops vis-à-vis combatants - and is possible for a more restricted and carefully sampled population.

\section{References}

Afrobarometer. (2008) Round Three Merged 18 Country Survey Data. Afrobarometer. Available at http://www.afrobarometer.org/data/round 3 merged. (Accessed October 9, 2013).

Agnew, John A. (1987) Place and Politics: The Geographical Mediation of State and Society. London: Allen and Unwin.

Bakke, Kristin, John O’Loughlin, and Michael D. Ward. (2009) Reconciliation in Conflict Affected Societies: Multilevel Modeling of Individual and Contextual Factors in the North Caucasus of Russia. Annals, Association of American Geographers 99 (5): 10331044.

Becchetti, Leonardo, Pierluigi Conzo, And Alessandro Romeo. (2011) Violence and Social Capital: Evidence of a Microeconomic Vicious Circle. Society for the Study of Economic Inequality, ECINEQ 2011 197. Available at http://ideas.repec.org/p/inq/inqwps/ecineq2011 197.html. (Accessed March 8, 2013).

\footnotetext{
${ }^{8}$ At the time of writing, Afrobarometer had just completed an initial survey in South Sudan.
} 
Berman, Eli, Michael Callen, Joseph H. Felter, and Jacob N. Shapiro. (2011a) Do Working Men Rebel? Insurgency and Unemployment in Afghanistan, Iraq, and the Philippines. Journal of Conflict Resolution 55 (4): 496528.

Berman, Eli, Jacob N. Shapiro, and Joeseph H. Felter. (2011b) Can Hearts and Minds Be Bought? The Economics of Counterinsurgency in Iraq. Journal of Political Economy 119 (4): 766819.

Blair, Graeme, C. Christine Fair, Neil Malhotra, and Jacob N. Shapiro. (2013) Poverty and Support for Militant Politics: Evidence from Pakistan. American Journal of Political Science 57 (1): 3048.

Braithwaite, Alex. (2010) Resisting Infection: How State Capacity Conditions Conflict Contagion. Journal of Peace Research 47 (3): 311319.

Braithwaite, Alex, and Shane D. Johnson. (2012) Space Time Modeling of Insurgency and Counterinsurgency in Iraq. Journal of Quantitative Criminology 28 (1): 3148.

Buhaug, Halvard, and Kristian Skrede Gleditsch. (2008) Contagion or Confusion? Why Conflict Clusters in Space. International Studies Quarterly 52 (2): 215233.

Buhaug, Halvard, Kristian Skrede Gleditsch, Helge Holterman, Gudrun Østby, and Andreas For $\varnothing$ Tollefsen. (2011) It's the Local Economy, Stupid! Geographic Wealth Dispersion and Conflict Outbreak Location. Journal of Conflict Resolution 55 (5): 814840.

Cederman, Lars Erik, Kristian Skrede Gleditsch, Idean Salehyan, and Julian Wucherpfennig. (2013) Transborder Ethnic Kin and Civil War. International Organization 67 (2): 389410.

Checkel, Jeffrey T. (2013) Transnational Dynamics of Civil Wars. In Transnational Dynamics of Civil Wars, edited by Jeffrey T. Checkel. New York: Cambridge University Press.

CIESIN. (2013) Gridded Population of the World v3, Center for International Earth Science Information Network. Available at http://sedac.ciesin.columbia.edu/data/set/gpw v3 population count. (Accessed October 9, 2013).

Condra, Luke N., Joseph H. Felter, Radha K. Iyengar, and Jacob N. Shapiro. (2010) The Effect of Civilian Casualties in Afghanistan and Iraq. National Bureau of Economic Research, Working Paper No. 16152.

Danneman, Nathan, and Emily H. Ritter. (2013) Contagious Rebellion and Preemptive Repression. Journal of Conflict Resolution 58 (2): 254279.

De Luca, Giacomo, and Marijke Verpoorten. (2012) From Vice to Virtue? Civil War and Social Capital in Uganda. Afrobarometer Working Paper No. 138. Available at http:// www.afrobarometer.org/files/documents/working papers/AfropaperNo138 2.pdf. (Accessed November 12, 2012).

Dercon, Steven, and Roxana Gutierrez Romero. (2012) Triggers and Characteristics of the 2007 Kenyan Electoral Violence. World Development 40 (4): 731744.

Dube, Oeindrila, and Juan Vargas. (2013) Commodity Price Shocks and Civil Conflict: Evidence from Colombia. Review of Economic Studies 80 (4): 13841421.

Falleti, Tulia G., And Julia F. Lynch. (2009) Context and Causal Mechanisms in Political Analysis. Comparative Political Studies 42 (9): 11431166.

Forsberg, Erika. (2008) Polarization and Ethnic Conflict in a Widened Strategic Setting. Journal of Peace Research 45 (2): 283300.

Gerring, John. (2007) The Mechanistic Worldview: Thinking Inside the Box. British Journal of Political Science 38 (1): 161179.

Gibler, Douglas M., and Alex Braithwaite. (2013) Dangerous Neighbors, Regional Territorial Conflict and the Democratic Peace. British Journal of Political Science 43 (4): 877887.

Gleditsch, Kristian Skrede, and Michael D. Ward. (2000) Peace and War in Time and Space: The Role of Democratization. International Studies Quarterly 43 (1): 129

Grossman, Herschel I. (1991) A General Equilibrium Model of Insurrections. The American Economic Review 81 (4): 912921.

Hutchison, Marc L., And Kristin Johnson. (2011) Capacity to Trust? Institutional Capacity, Conflict, and Political Trust in Africa, 2000 2005. Journal of Peace Research 48 (6): 737752.

Iacus, Stefano M., Gary King, and Giuseppe Porro. (2011) Causal Inference without Balance Checking: Coerced Exact Matching. Political Analysis 20: 124.

Kalyvas, Stathis N. (2006) The Logic of Violence in Civil War. New York: Cambridge University Press.

Kalyvas, Stathis N., And Matthew A. Kocher. (2007) Ethnic Cleavages and Irregular War: Iraq and Vietnam. Politics $\mathcal{E}^{2}$ Society 35 (2): 183223.

Kanyinga, Karuti. (2009) The Legacy of the White Highlands: Land Rights, Ethnicity and Post 2007 Election Violence in Kenya. Journal of Contemporary African Studies 27 (3): 325344.

Kocher, Matthew A., Thomas B. Pepinsky, and Stathis N. Kalyvas. (2011) Aerial Bombing and Counterinsurgency in the Vietnam War. American Journal of Political Science 55 (2): 201218. 
Levi, Margaret, and Laura Stoker. (2000) Political Trust and Trustworthiness. Annual Review of Political Science 3 (1): 475507.

Linke, Andrew M. (2013) The Aftermath of an Election Crisis: Kenyan Attitudes and the Influence of Individual Level and Locality Violence. Political Geography 37: 513.

Linke, Andrew M., And John O'Loughlin. (2015) Reconceptualizing, Measuring, and Evaluating Distance and Context in the Study of Conflicts Using Survey Data from the North Caucasus of Russia. International Studies Review 17 (1): 112130.

Linke, Andrew M., Frank D. Witmer, and John O'Loughlin. (2012) Space Time Granger Analysis of the War in Iraq: A Study of Coalition and Insurgent Action Reaction. International Interactions 38: 402425 .

Lyall, Jason. (2010) Does Indiscriminate Violence Incite Insurgent Attacks? Evidence from Chechnya. Journal of Conflict Resolution 53 (3): 331362.

Lyall, Jason, And Isiah Wilson. (2009) Rage Against the Machines: Explaining Outcomes in Counterinsurgency Wars. International Organization 63 (1): 67106.

Maves, Jessica, and Alex Braithwaite. (2013) Autocratic Institutions and Civil Conflict Contagion. Journal of Politics 75 (2): 478490.

Miguel, Edward, Shanker Satyanath, and Ernest Sergenti. (2004) Economic Shocks and Civil Conflict: An Instrumental Variables Approach. Journal of Political Economy 112 (4): 725753.

Most, Benjamin, and Harvey Starr. (1980) Diffusion, Reinforcement, Geopolitics and the Spread of War. American Political Science Review 74 (4): 932946.

Murdoch, James C., And Todd SAndler. (2004) Civil Wars and Economic Growth: Spatial Dispersion. American Journal of Political Science 48 (1): 138151.

O'Loughlin, John, And Luc Anselin. (1991) Bringing Geography Back to the Study of International Relations: Spatial Dependence and Regional Context in Africa, 19661978. International Interactions 17: 2961.

O’Loughlin, John, and Gerard ÓTuathail. (2009) Accounting for Separatist Sentiment in Bosnia Herzegovina and the North Caucasus of Russia: A Comparative Analysis of Survey Responses. Ethnic and Racial Studies 32 (4): 561615.

O'Loughlin, John, and Frank D. Witmer. (2012) The Diffusion of Conflicts in the North Caucasus of Russia, 1999 2010. Environment and Planning A 44: 23792396.

Østby, Gudrun, Ragnhild Nord̊̊s, and Jan Ketil RøD. (2009) Regional Inequalities and Civil Conflict in Sub Saharan Africa. International Studies Quarterly 53 (2): 301324.

Prunier, Gerard. (2009) Africa's World War: Congo, the Rwandan Genocide, and the Making of a Continental Catastrophe. Oxford, UK: Oxford University Press.

Raleigh, Clionadh, and Håvard Hegre. (2009) Population Size, Concentration, and Civil War. A Geographically Disaggregated Analysis. Political Geography 28 (4): 224238.

Raleigh, Clionadh, Andrew M. Linke, Håvard Hegre, and Jaokim Karlsen. (2010) Introducing ACLED: An Armed Conflict Location and Event Dataset. Journal of Peace Research 47 (5): 651660.

Reed, William, and Daina Chiba. (2010) Decomposing the Relationship between Contiguity and Militarized Conflict. American Journal of Political Science 54 (1): 6173.

Rosenbaum, Paul R. (1989) Optimal Matching for Observational Studies. Journal of the American Statistical Association 84 (408): 10241032.

SAlehyan, Idean. (2009) Rebels without Borders. Ithaca, NY: Cornell University Press.

Schutte, Sebastian, and Karsten Donnay. (2014) Matched Wake Analysis: Finding Causal Relationships in Spatiotemporal Event Data. Political Geography 41 (1): 110.

Schutte, Sebastian, and Nils B. Weidmann. (2011) Diffusion Patterns of Violence in Civil Wars. Political Geography 30 (3): 143152

Shapiro, Jacob N., and Nils B. Weidmann. (2011) Talking about Killing: Cell Phones, Collective Action, and Insurgent Violence in Iraq. Working paper. Available at http://www.princeton.edu/ jns/papers/SW 2011 Cell Phones Insurgency 31MAY11.pdf. (Accessed June 11, 2012).

Siverson, RandolPh, AND HARvey STARr. (1990) Opportunity, Willingness, and the Diffusion of War. American Political Science Review 84 (1): 4767.

Straus, Scott. (2012) Wars Do End! Changing Patterns of Political Violence in Sub Saharan Africa. African Affairs 111 (443): 179201.

Theisen, Ole Magnus. (2012) Climate Clashes? Weather Variability, Land Pressure, and Organized Violence in Kenya, 1989 2004. Journal of Conflict Resolution 49: 8196.

Toft, Monica D., And Yuri M. Zhukov. (2012) Denial and Punishment in the North Caucasus: Evaluating the Effectiveness of Coercive Counter Insurgency. Journal of Peace Research 49 (6): 785800.

Tollefsen, Andreas For $\varnothing$, AND Halvard Buhaug. (2015) Insurgency and Inaccessibility. International Studies Review 17 (1): 625. 
Ward, Michael D., Brian Greenhill, and Kristin Bakke. (2010) The Perils of Policy by p Value. Journal of Peace Research 47 (4): 363375.

Weidmann, Nils B., And Michael D. Ward. (2010) Predicting Conflict in Space and Time. Journal of Conflict Resolution 54 (6): 883901.

Wilkinson, Steven I. (2004) Votes and Violence: Electoral Competition and Ethnic Riots in India. New York: Cambridge University Press.

Zhukov, Yuri M. (2012) Roads and the Diffusion of Insurgent Violence: The Logistics of Conflict in Russia's North Caucasus. Political Geography 31 (3): 144.

Zhunov, Yuri M. (2013) An Epidemic Model of Violence and Public Support in Civil War. Conflict Management and Peace Science 30 (1): 2452.

\section{Appendix}

\section{Spatial Dependencies and SUTVA Violations}

As we have explained above, we are concerned with the second element of the Stable Unit Treatment Value Assumption (SUTVA), which stipulates that an administrative unit could be influenced by the treatment condition of other units. We model the effect that would constitute a SUTVA violation as an indicator in the matching procedure that precedes the SATT estimation. In other words, in our analysis we do not necessarily compare units that are statistically independent of one another, but that are equally affected by previous treatment.

To clarify, assume that we have locations $A-P$ distributed across the coordinate grid in Figure A1. Observations $B, E$, and $F$ define the neighborhood of unit $A$. Violation of the SUTVA second assumption would exist if treatment status of unit $A\left(T_{A}\right)$ affects conflict in location $B$ at time $t$, whether or not treatment status of $B\left(T_{B}\right)=1$ or 0 . Because $T_{A}$ is measured as prior $(t-1)$ conflict in the neighborhood of $B, E$, and $F$, this treatment could influence later conflict in $B$. We therefore include previous conflict (at $t-1$ ) in $B$ as a pre-treatment control in the effect estimate for unit B. This eliminates the possibility of SUTVA violation by returning an estimate of $T_{B}$ that is not biased by $T_{A}$.

Consider now the proposition that above-average approval of violence constitutes a treatment condition leading to higher subsequent levels of violence (proposition two). If high levels of violence approval in unit $A$ led to unknown changes in nearby unit $B$ that in turn affected the number of conflict events in unit $B$ at a later date, we would have a biased estimate of $T_{B}$ because of spillover effects from $T_{A}$ into other observations. In this case, there is a possible violation of the second SUTVA assumption for the attitude mechanism treatment. But how would this materialize?

One possibility is that in unit $A$ and neighboring unit $B$, there are hostilities associated with some enduring and ongoing tension that has resulted in past violence. Imagine that because of a perceived threat from unit $A$, people in $B$ begin buying and storing weapons. This availability of weapons could influence the number of conflict events in $B$ and would be unobserved (we do not have data for how many guns people buy per month). If residents of area $B$ perceive a threat from $A$ in this manner, it is likely that prior violence between the two has contributed to mutual fear (for example, tit-for-tat types of violence, or reprisal acts among ethnic pastoralist militia). Recall that SUTVA is only violated when $T_{A}$ acts upon the estimate for $T_{B}$ in an unobserved way, and is also not accounted for by pre-treatment covariates. By controlling for prior violence in each unit, those observations where tit-for-tat violence may be taking place are compared only with other administrative areas that have also experienced substantial previous violence (within the CEM matched strata). If symbolic signaling 


\begin{tabular}{|c|c|c|c|}
\hline$A$ & $B$ & $C$ & $D$ \\
\hline$E$ & $F$ & $G$ & $H$ \\
\hline$I$ & $J$ & $K$ & $L$ \\
\hline$M$ & $N$ & $O$ & $P$ \\
\hline
\end{tabular}

FiG. A1. Conceptual Representation of Observational Spatial and Temporal Data in Geographic Units A $P$

(Note We present explanations of our solution for an unbiased treatment effect estimate in the presence of possible stable unit treatment value assumption violation).

activity or entrepreneurial ethnic-outbidding by leaders is also associated with previous levels of violence, we have also controlled for these influences.

\section{Alternative Model Estimate}

The models below in Figure A2 are replications of the exact models in our main analysis, but with a different definition of above-average support for violence in administrative units. Here, we have defined the percentage of support for violence as "above average" when compared to the country's mean level of support (rather than the continent-wide average). Overall, the results for the key combined term are consistent for the model without country-level fixed effects. There is a statistically significant and positive effect (Panel A), but the magnitude is not greater than either the attitude or nearby conflict indicator alone. Also, the combined term is not statistically significant at the $95 \%$ level with fixed-effects terms (Panel B).

\section{Full Balance Statistics}

In Table A1, we present the complete balance statistics for the matched data used in the SATT estimates in the main article. In the main body of the paper, we present the $L 1$ and LCS values only.

\section{Data Source Comparison}

We compare the preferred conflict event data set to UCDP GED in this section. To manage the date structure of UCDP GED, we parse the date into pre- and post-survey periods and conduct the spatial join with administrative units using several steps. First, we drop events with poor geographic or poor temporal precision. Second, we include events in the pre-survey count if the end date falls within the one-year window preceding the survey enumeration period in a given 

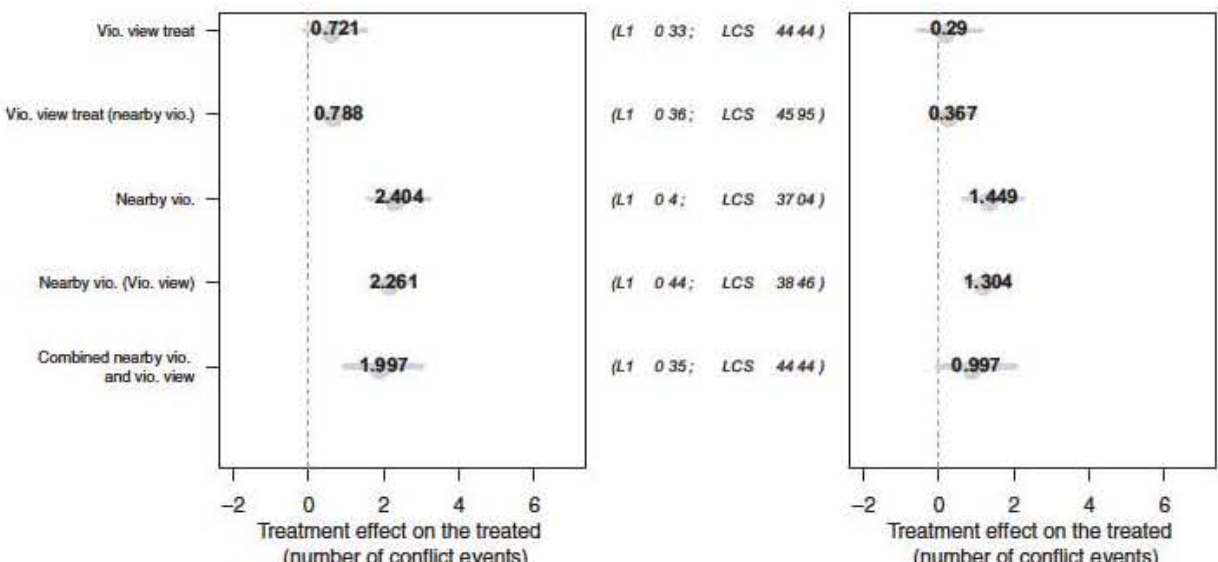

Fig. A2. Replication of the Results in the Main Article Figure Using a Country Specific Measure of Violence Approval. Average Treatment Effects of Five Indicators Testing the Three Main Propositions

(Notes. Balance improvement scores for the matched data used in each model are presented in the center ( $L 1$ and LCS). We present $95 \%$ confidence intervals. The right panel of the figure presents the treatment effect es timates after including country-level fixed effects. Matched data (and balance diagnostics) are the same for both because the fixed effects are used after the initial coarsened exact matching matching procedure. "Vio." and "Treat" mean violence and treatment in the varable names, respectively).

\section{Compare with UCDP GED}

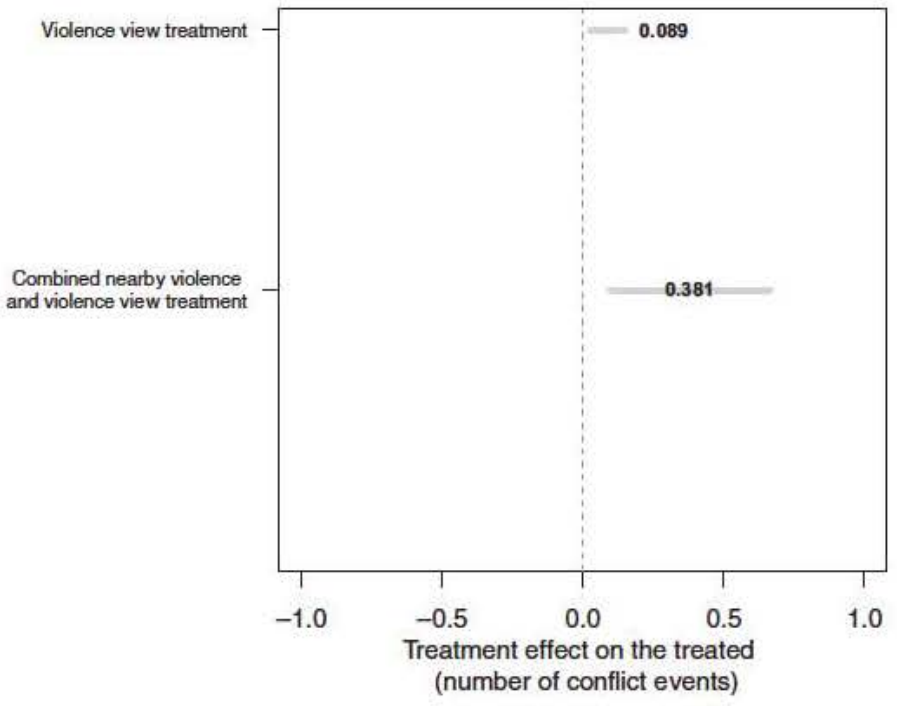

Fic. A3. Key Treatment Effect Estimates Reproduced with the UCDP GED Conflict Event Counts, Controlling for Violence Before the Survey, Population, and Socioeconomic Status

(Note Scale of axis is different than the main figure, and icons are smaller for interpretation). 
TABle A1. Balance Statistics (by Indicator and Each Main Model) for Models 15 in the Analysis Above

\begin{tabular}{|c|c|c|c|c|c|c|c|}
\hline & Statistic & L1 & Min & $25 \%$ & $50 \%$ & $75 \%$ & $\operatorname{Max}$ \\
\hline \multicolumn{8}{|l|}{ M1 } \\
\hline Population & 0.20 & 0.00 & 2.17 & 0.45 & 0.66 & 0.31 & 0.12 \\
\hline Low SES & 0.02 & 0.02 & 0.00 & 0.00 & 0.00 & 0.00 & 0.00 \\
\hline Previous violence & 6.49 & 0.03 & 0.00 & 0.00 & 1.00 & 7.00 & 134.00 \\
\hline \multicolumn{8}{|l|}{ M2 } \\
\hline Population & 0.20 & 0.00 & 2.17 & 0.45 & 0.66 & 0.31 & 0.12 \\
\hline Low SES & 0.02 & 0.02 & 0.00 & 0.00 & 0.00 & 0.00 & 0.00 \\
\hline Previous violence & 6.49 & 0.03 & 0.00 & 0.00 & 1.00 & 7.00 & 134.00 \\
\hline Neighboring violence & 0.20 & 0.20 & 0.00 & 1.00 & 0.00 & 0.00 & 0.00 \\
\hline \multicolumn{8}{|l|}{ M3 } \\
\hline Population & 0.62 & 0.00 & 2.05 & 0.77 & 0.90 & 0.56 & 0.12 \\
\hline Low SES & 0.02 & 0.02 & 0.00 & 0.00 & 0.00 & 0.00 & 0.00 \\
\hline Previous violence & 7.41 & 0.02 & 0.00 & 0.00 & 2.00 & 7.00 & 157.00 \\
\hline \multicolumn{8}{|l|}{ M4 } \\
\hline Population & 0.62 & 0.00 & 2.05 & 0.77 & 0.90 & 0.56 & 0.12 \\
\hline Low SES & 0.02 & 0.02 & 0.00 & 0.00 & 0.00 & 0.00 & 0.00 \\
\hline Previous violence & 7.41 & 0.02 & 0.00 & 0.00 & 2.00 & 7.00 & 157.00 \\
\hline Above mean support & 0.23 & 0.23 & 0.00 & 0.00 & 1.00 & 0.00 & 0.00 \\
\hline \multicolumn{8}{|l|}{ M5 } \\
\hline Population & 0.29 & 0.00 & 2.05 & 0.63 & 0.63 & 0.36 & 0.12 \\
\hline Low SES & 0.02 & 0.02 & 0.00 & 0.00 & 0.00 & 0.00 & 0.00 \\
\hline Previous violence & 8.77 & 0.03 & 0.00 & 0.00 & 3.00 & 10.00 & 134.00 \\
\hline
\end{tabular}

Table A2. Simple Differences in Event Count Means of Treatment and Control Status for Three Propositions Using UCDP GED Conflict Event Data Instead of Our Preferred Data

\begin{tabular}{|c|c|c|}
\hline Proposition Indicator & Mean Event Count (Treatment & Control) \\
\hline Violence approval & 0.379 & \\
\hline Neighboring violence & 1.488 & \\
\hline Violence approval and neighboring violence & 1.932 & \\
\hline
\end{tabular}

country. Third, we include conflict events in the post-survey count if the start date falls within the one-year window following the survey enumeration period. Any date ranges that span the enumeration period are clearly problematic and cannot be used.

In Table A2, we present the simple differences between treatment and control group conflict event counts (a replication of main text Table 2). In general, the results of this simple calculation are in line with our main analysis. The number of events where the dual condition of high approval of violence and neighboring violence is met is higher than the number of conflict events otherwise. Importantly, the number of events for the test of proposition three is even higher than the number of events for either of the other treatment conditions alone.

In Figure A3, we reproduce the estimates for main propositions using the UCDP GED conflict data. Both the effect of sentiments about using violence and the combined effect of nearby violence with high levels of support for violence are positive and statistically significant. These results mirror our main findings, but the estimates are lesser in magnitude. As above, all models control for previous violence in the administrative area, population size, and socioeconomic status. 